\title{
ESTRATÉGIAS DE ENSINO NA EDUCAÇÃO SUPERIOR
}

\author{
Amanda Bellettini Munari ${ }^{1}$ \\ Ives Fiegenbaum ${ }^{2}$ \\ Ricardo Luiz de Bittencourt ${ }^{3}$
}

\section{INTRODUÇÃO}

A ampliação da oferta de vagas na educação superior tem crescido consideravelmente no Brasil uma vez que a tendência estabelecida pelos organismos internacionais é a de "universitarizar" as profissões. A experiência de ensino compartilhada neste artigo é resultado de um trabalho sobre Estratégias de Trabalho Docente realizado no âmbito da disciplina de Metodologia do Ensino Superior do Programa de Pós-Graduação em Ciências Ambientais (PPGCA) da Universidade do Extremo Sul Catarinense (UNESC).

A disciplina de Metodologia do Ensino Superior propõe a capacitação do futuro professor universitário, abordando a prática da docência em nível superior, sob aspectos didáticos, metodológicos, planejamento e avaliação da aprendizagem, articulando teoria e prática.

A partir das discussões e seminários realizados em aula, formaramse duplas com o propósito de ministrar uma aula em um curso de ensino superior. Por decisão coletiva foi escolhida a estratégia Aula Expositiva Dialogada, a qual foi aplicada na disciplina de Endomarketing no curso de Gestão Comercial sobre responsabilidade socioambiental.

A utilização da estratégia de ensino se justifica, pois possibilita a promoção de diálogo entre o docente e o aluno, de modo que o aluno passa a fazer parte do processo de ensino-aprendizagem na medida em que ele traz para sala de aula seus saberes e suas experiências vividas. A construção do conhecimento acontece através da troca de informações, de questionamentos, de confronto e da reflexão da sua realidade, permitindo que o aluno faça a

\footnotetext{
${ }^{1}$ Universidade do Extremo Sul Catarinense - UNESC. E-mail: abm@unesc.net

${ }^{2}$ Universidade do Extremo Sul Catarinense - UNESC. E-mail: ives@unesc.net

${ }^{3}$ Universidade do Extremo Sul Catarinense - UNESC. E-mail: rlb@unesc.net
} 
reflexão da sua prática e se perceba como sujeito capaz de compreender e transformar as realidades.

O objetivo desse trabalho é o de apresentar reflexões sobre os processos de ensino na educação superior interseccionando teoria e prática, estabelecendo relações entre os estudos teóricos e a experiência de docência.

O trabalho está dividido em duas partes, a primeira parte destaca a formação do professor universitário e sua contribuição para a vida profissional do futuro professor. A segunda parte destaca a importância das estratégias de ensino nas atividades docentes.

\section{FORMAÇÃO DO PROFESSOR UNIVERSITÁRIO}

O exercício da atividade docente na educação superior é um processo complexo por conta dos múltiplos fatores que lhe constituem. Num mundo globalizado que requer a formação de profissionais mais capacitados torna premente a preocupação com a formação de professores.

Vale destacar a importância da formação docente para o ensino superior, principalmente para quem é o aprendiz, e quando se busca a qualidade dos cursos, pois, muitos professores universitários carecem de formação pedagógica ao valorizarem a pesquisa em detrimento do ensino. Essa reflexão ganha mais sentido quando se leva em consideração o papel das avaliações externas e internas dos cursos de graduação.

Quando digo que os cursos são carentes de formação pedagógica quero dizer que cursos bacharéis não possuem as matérias ditas como "pedagógicas" oferecidas nos cursos de licenciatura, ou para um melhor entendimento, as matérias que orientam o futuro professor a ser um professor (BASTOS; ORO, 2012).

Dessa forma é necessário conhecer o processo de formação do professor universitário oriundo dos cursos de bacharelado, com uma reflexão a respeito dos aspectos pedagógicos considerados essenciais para a formação e a ação docente na universidade. Muitos profissionais bacharéis ao assumirem a docência na educação superior se deparam com muitas dificuldades, sobretudo na condução do processo ensino aprendizagem. 
É nessa perspectiva que as produções a respeito da temática saberes docentes têm ocupado papel de destaque na formação de professores, o que é atribuído, em grande parte, ao seu potencial no desenvolvimento de ações formativas que vão além de uma abordagem acadêmica, envolvendo as dimensões pessoal, profissional e organizacional da profissão docente (BIAJONE; ALMEIDA, 2007).

A formação para o exercício do ensino superior pode ser vista como um campo em que há muito por se fazer em termos de pesquisas e práticas. Quando existe alguma formação para a docência neste grau de ensino se encontra circunscrita a uma disciplina de Metodologia do Ensino Superior, nos momentos da pós-graduação, com carga horária média de 60 horas (MIZUKAMI; FERENC, 2005).

No entanto, é fundamental que os aspectos didáticos pedagógicos estejam presentes na formação buscando saber até que ponto qualifica a formação e atuação docente. Se tomarmos os dados de avaliação institucional realizado pelas universidades teremos elementos importantes para redirecionar as práticas de formação continuada. São nos relatórios de avaliação institucional que se pode buscar elementos para a construção de um programa de formação continuada que toma efetivamente a realidade como ponto de partida.

Embora os professores possuam experiências significativas e trajetória de estudos em sua área de conhecimento especifica, é comum nas diferentes instituições de ensino superior, o predomínio do "desespero e até um desconhecimento científico do que seja o processo de ensino e de aprendizagem, pelo qual passam a ser responsáveis a partir do instante em que ingressam na sala de aula" (MIZUKAMI; FERENC, 2005, p. 05).

A relação dos docentes com os saberes não se reduz a uma função de transmissão dos conhecimentos já constituídos. Sua prática integra diferente saberes, com os quais o corpo docente mantém diferentes relações. O saber docente pode ser definido um saber plural, formado pelo heterogêneo, mais ou menos coerente, de saberes oriundos da formação profissional e de saberes disciplinares, curriculares e experienciais (TARDIF, 2007).

Tardif (2007), discute as relações entre os conhecimentos universitários e os saberes experimentais dos professores, os novos modelos 
de formação profissional e seus limites, as relações entre carreira profissional e aprendizagem docente. O mesmo usa uma metodologia de pesquisa empírica, onde realizada junto aos professores bem como as questões teóricas sobre a natureza dos saberes que são impulsionados e utilizados em seu trabalho cotidiano.

A profissão de professor universitário requer, ainda, a produção de conhecimentos de diferentes naturezas, por isto se investe em cursos de aperfeiçoamento. Organizam-se congressos reuniões, seminário em áreas específicas, cujo objetivo é promover o desenvolvimento, a socialização da produção, das descobertas e, pode-se dizer, a formação cientifica do professor universitário.

A atividade profissional dos professores de profissão deve ser considerada como um espaço prático de produção, de transformação e de mobilização de saberes e, consequentemente, de teorias, de conhecimentos e de saber-fazer específicos ao ofício de professor (BIAJONE; ALMEIDA, 2007).

No caso da docência universitária, os saberes são também atingidos pela estrutura de poder que permeia as distintas profissões e o prestígio que é dado às diferentes dimensões da carreira. Considerando as funções tradicionais de pesquisa e ensino, espera-se que os professores construam saberes que respondam a essas duas demandas, para exercerem sua profissão com êxito.

Em contrapartida, há experiências de assessoria pedagógica que trazem professores de outros campos profissionais tidos como "modelos" para formar outros professores. Argumenta-se, por exemplo, que um bom professor de fisioterapia consegue estabelecer um diálogo melhor com outro professor fisioterapeuta iniciante do que um professor do campo da educação.

Há que se compreender que uma assessoria pedagógica deve dar conta de pensar e encaminhar estratégias formativas que vão ao encontro das reais necessidades dos professores. Ao mesmo tempo, uma assessoria pedagógica pode construir coletivamente outras necessidades docentes que contribuam para desnaturalizar as práticas pedagógicas entendidas como tradicionais e incompatíveis com contexto atual. 
A prática docente não é apenas um objeto de saber das ciências da educação, ela é também uma atividade que mobiliza diversos saberes que podem ser chamados de pedagógicos (TARDIF, 2007).

O exercício da profissão, a prática docente, continuamente, exigenos a interlocução com o outro, haja vista os desafios de diferentes ordens que a compõem, tais como compreender a cultura organizacional, as diversas regulações do campo, as regras que definem os desempenhos; a seleção dos conhecimentos mais significativos e a sua transposição para a prática da sala de aula; o desenvolvimento de práticas pedagógicas que propiciem bons resultados.

Segundo Tardif (2007) "embora ensinem a grupos, os professores não podem deixar de levar em conta as diferenças individuais, pois são os indivíduos que aprendem, e não os grupos (p.129)".

As ideias de Tardif aqui apresentadas contribuem para pensar a profissão docente como uma profissão que lida diretamente com pessoas, com características individuais, com modalidades de aprendizagem que caracterizam cada estudante que o professor interage.

Podemos visualizar, quando analisamos o docente universitário no cotidiano institucional, um processo de intensificação de seu trabalho, indicando que de um lado, a escassez de tempo de preparação, o que apresenta como solução, 'traduções simplificadas de saberes especializados impostos externamente'. Essa intensificação do trabalho docente contribui para fragilizar as relações que se estabelecem entre professores e estudantes. $O$ acúmulo de tarefas pode diminuir a sensibilidade necessária ao profissional que trabalha basicamente com pessoas.

O professor universitário é chamado a contribuir tanto no campo de ensino, como, também, da pesquisa, da extensão, da administração, quase que simultaneamente. Essa intensificação do trabalho docente leva esses profissionais a buscarem os caminhos mais fáceis para executarem suas tarefas. Um ensino sem pesquisa se transforma em uma pedagogia reprodutivista muito baseada em modelos e na sua repetição. Um ensino sem extensão também se descola da realidade e não contribui para a sua transformação. Assim surgem questionamentos sobre como formar o professor universitário? Que saberes são colocados em movimento nos processos de 
construção da docência? Como estabelecer a articulação entre formação inicial e continuada?

Num esforço preliminar de sistematizar algumas reflexões sobre os saberes do docente universitário, é possível afirmar que muitas universidades têm se preocupado com a formação de seus docentes criando programas de formação continuada. Nesses programas são tematizados reflexões teóricas e práticas sobre o processo ensino aprendizagem na educação superior.

A docência universitária é uma atividade complexa. Só quando for reconhecida essa complexidade poder-se-á avançar em processos de qualificação mais efetivos. Exige saberes específicos que têm um forte componente de construção na prática. Entretanto é uma prática que não se repete, é sempre única (CUNHA, 2015).

Desse modo, as universidades e os centros universitários têm responsabilidade social com a formação de professores e com a educação do nosso país. E mesmo em contextos adversos, é possível construir práticas de formação inicial e continuada comprometidas com um ensino de qualidade, que não perca de vista a dimensão ética e política, bem como as discussões e reflexões sobre os fins da educação (BIAJONE; ALMEIDA, 2007).

Portanto, os processos de formação de professores para a educação superior compreendem um conjunto de conhecimentos que passas pelas reflexões sobre os fundamentos teóricos da docência até a implementação de estratégias que qualifiquem o processo ensino aprendizagem.

\section{IMPORTÂNCIA DAS ESTRATÉGIAS DE ENSINO}

As mudanças sociais, políticas, econômicas e culturais têm trazido para o campo da educação e da formação profissional muitos desafios. A ampliação do uso de novas tecnologias tem impactado no comportamento dos estudantes diante dos processos educativos a que estão submetidos e também no posicionamento dos professores no processo ensino-aprendizagem.

O estudo sobre as diferentes linhas pedagógicas, no caso as abordagens, no ensino podem oferecer diretrizes à ação docente, levando em conta que preparação que cada professor faz é única e não amovível. Ainda, segundo Mizukami (1986), certas abordagens apresentam um referencial 
filosófico e psicológico claro, ao ver outras que são intuitivas ou respaldadas na prática, ou na cópia de modelos.

Para compreender a importância das estratégias de ensino na educação superior é necessário revisitar os estudos sobre abordagens de ensino. Com esse intuito nos apoiamos nas reflexões de Mizukami (1986) acerca das diferentes abordagens de ensino que sustentam o trabalho docente. De acordo com Muzukami (1986) as abordagens de ensino são:

A abordagem tradicional que trata de uma geração e uma aplicação educacional que ficam no tempo, em suas várias formas, e que decorre em um quadro distinto das outras formas de abordagem.

A abordagem comportamentalista designa-se por um conhecimento 'descoberto', onde a própria pessoa encontra o que já estava corrente na realidade exterior. Os comportamentalistas julgam esta experiência fundamental do conhecimento, sendo o mesmo resultado evidente da experiência.

A abordagem humanista coloca o sujeito como o principal construtor do conhecimento humano. A mesma enfatiza o aumento resultante do desenvolvimento da personalidade do ser humano e sua capacidade de agir como uma pessoa integrada.

$\mathrm{Na}$ abordagem cognitivista mostra a organização do conhecimento, onde a metodologia de informações estilos de pensamento ou estilos cognitivos, bem como comportamentos referentes à tomada de decisões, ou seja, e um processo educacional, onde homem e mundo são analisados juntamente e o conhecimento é uma construção continua.

Por fim, tem-se a abordagem sociocultural, onde se pode referenciar o autor Paulo Freire, dando evidencia aos aspectos sócio-politico-cultural, tendo uma apreensão com a cultura popular, tendo em vista que esta apreensão já vem desde muitos anos atrás e com continuo aumento até os dias atuais, com o objetivo de "possibilitar uma real participação do povo enquanto sujeito de um processo cultural" (p.86).

Deste modo, por meio das analises realizadas sobre as diversas abordagens do processo de ensino e aprendizagem Mizukami constata que algumas linhas teóricas são mais explicativas sobre a feição de outros, 
notando-se a possibilidade de relacionar várias propostas de explicação do processo educacional.

A autora ainda faz uma critica ao método de formação dos professores, dizendo que o estudado e sabido por eles não tem a ver com a prática pedagógica e sua colocação frente ao processo educacional. Assim sendo, a experiência pessoal do educador em sala de aula seria a base do professor, onde se daria um fim a constante discussão entre teoria e prática para o ensinamento.

No processo ensino-aprendizagem é recomendável que se dê ao aluno a oportunidade para exercitar seu pensamento e explorar relações. As operações do pensamento e as estratégias de ensino são variáveis centrais e indissociáveis que permeiam esse processo (SANTOS; MEIRA, 2015).

As operações de pensamento sempre estão presentes independentemente do método de ensino adotado. Elas são ações mentais pelas quais 0 indivíduo operacionaliza e solidifica 0 aprendizado (ANASTASIOU; ALVES, 2005)

Segundo Santos e Meira (2015), ao selecionar as ações contidas em diferentes estratégias de ensino, a aprendizagem propõe ao aluno o exercício de processos mentais relacionados à lógica do conhecimento que fundamenta e direciona o conteúdo que se pretende abordar.

Pode-se dizer que estratégias de ensino e operações de pensamento formam um único componente do processo ensino-aprendizagem, visto que todo conteúdo possui uma lógica interna, uma forma que lhe é própria e que precisa ser captada e apropriada para sua efetiva compreensão.

E neste contexto, a estratégia de ensino aqui denominada de aula expositiva dialogada, utilizada neste estudo, apresenta algumas das operações de pensamento de Louis Raths, tais como: a obtenção e organização de dados, interpretação, critica, decisão, comparação e resumo. Esta estratégia proporciona uma parceria entre professores e alunos no enfrentamento do conteúdo, estabelecendo desta forma uma relação de troca de conhecimentos e experiências entre estes (ANASTASIOU; ALVES, 2005).

\section{SOBRE EXPERIÊNCIA DOCENTE}


A partir da formação de duplas, tomou-se a Aula Expositiva Dialogada como estratégia de ensino para ministrar uma aula em um curso de ensino superior. Neste caso, a dupla foi formada por dois engenheiros ambientais. O que se buscou com esta experiência foi proporcionar aos mestrandos a possibilidade de vivenciar a docência na educação superior da forma mais concreta possível. Primeiramente foi apresentada uma pesquisa bibliográfica, em relação ao tema de estudo, colocando os estudantes em contato direto com tudo que foi escrito, dito ou filmado sobre o assunto pelo professor da disciplina de Metodologia do Ensino Superior (MARCONI; LAKATOS, 2010).

A estratégia de ensino escolhida para realização da experiência, a Aula Expositiva Dialogada é uma técnica que desafia a atividade e a iniciativa dos alunos sem prescindir da iniciativa do professor. A estratégia favorece 0 diálogo entre professor e alunos, e dos alunos entre si, sem cair numa prática permissiva e considera os interesses e experiências dos alunos sem desviar-se da sistematização lógica dos conteúdos previstos nos programas de ensino.

É imprescindível que o professor promova a articulação entre o contexto educacional e a prática social, permitindo ao aluno a aquisição do saber sistematizado, a reelaboração desse saber e a produção de novos conhecimentos.

A aula dialogada, além da troca de informações entre docentes e alunos, é o primeiro passo para facilitar a assimilação do conhecimento e veicular à realidade do aluno a conteúdos significativos. A participação do aluno é essencial para o bom desenvolvimento da aula (MIZUKAMI, 1986).

A aula tida como experiência deste trabalho foi ministrada no segundo semestre de 2015, na disciplina de Endomarketing no curso de Gestão Comercial (presencial) da Universidade do Extremo Sul Catarinense (UNESC). O curso de gestão comercial tem como foco o ensino de técnicas mercadológicas, financeiras, de vendas de planejamento estratégico, bem como ferramentas para gerir o próprio negócio ou atuar nas mais variadas áreas comerciais das organizações.

A disciplina de Endomarketing objetiva mostrar ao futuro tecnólogo em Gestão Comercial a importância do Endomarketing como ferramenta à obtenção de sucesso nas organizações empresariais, capacitando-o a intervir 
interdisciplinarmente em projetos de endomarketing e contribuir em todas as etapas deste, do planejamento estratégico à execução, para garantir à empresa excelência em sua atuação. Esta estratégia consiste em uma exposição do conteúdo, que neste caso foi sobre responsabilidade socioambiental, com a participação ativa dos estudantes, cujo conhecimento prévio deve ser considerado e pode ser tomado como ponto de partida.

Este tema é importante aos futuros gestores, pois possibilita aos mesmos um conhecimento sobre uma pessoa ou grupo que possui participação, investimento ou ações e interesse em uma determinada empresa ou negócio em relação ao meio ambiente. Para ser mais especifico, seria a responsabilidade ambiental dos stakeholders que no inglês stake significa interesse, participação, risco enquanto holder significa aquele que possui. É neste momento que o professor leva os alunos a questionarem, interpretarem e discutirem o objetivo de estudo, a partir do reconhecimento e do confronto com a realidade. Através disto deve-se provocar análise crítica por meio dos mesmos, resultando na produção de novos conhecimentos e ainda, propondo a superação da passividade e imobilidade intelectual dos estudantes (ANASTASIOU; ALVES, 2005). Após, foi solicitado que os alunos escrevessem uma pequena resenha, sobre a temática discutida em aula para ser socializada ao grande grupo com objetivo de detalhar os principais pontos discutidos em aula em uma visão critica, de modo a conceituar o assunto a partir das referências expostas elencando as principais questões abordadas.

\section{CONCLUSÃO}

Os estudos realizados para a construção desse artigo foram importantes para refletir sobre a importância da relação dialética entre teoria e prática. Estabelecer contato com autores do campo da educação e relacionálos com a experiência docente e aos conhecimentos específicos da formação de engenheiros foi desafiador e contribuiu significativamente para a compreensão da docência como um processo de construção.

A experiência teve a participação continua dos alunos, onde os mesmos dialogaram sobre o assunto, trazendo para sala de aula suas vivencias cotidianas e buscando de um modo ou de outro interagir com os 
professores na medida em que os mesmos apresentavam o conteúdo. A participação ativa dos alunos e o diálogo constante entre eles e os professores mostra que a aprendizagem é concebida através da reflexão do tema pelo aluno que busca desenvolver estratégias que possibilitem a solução de uma situação problema, por exemplo.

Os exemplos trazidos pelos alunos de seu cotidiano para ilustrar e discutir o assunto em sala de aula foi de grande importância, pois os mesmos acabaram por ter soluções e estratégias nunca pensadas anteriormente e que podem auxiliá-los em seu trabalho de modo a resolver possíveis problemas.

A experiência de ministrar a aula e aplicar a estratégia de ensino foi de grande valia, pois se teve a oportunidade de vivenciar o cotidiano docente, refletir sobre a atividade do professor, de modo a traçar perspectivas que podem potencializar o conhecimento histórico, social, cultural e organizacional da pratica docente, bem como perceber nossa responsabilidade de formar os futuros profissionais que atuarão em nossa sociedade.

Ainda, pode-se dizer que para dois engenheiros ambientais a experiência foi bem interessante e o fato dos alunos se interessarem pelo conteúdo, que foi totalmente teórico - não vivenciado todos os dias em nossa graduação, por ser da área de exatas - também contribuiu.

A socialização do conhecimento, de ajudar outra pessoa a entender algo era vivenciada em nosso cotidiano na graduação em aulas de cálculo, onde ficávamos passando dicas para os colegas nos intervalos de aula, tentando ajudar na resolução dos exercícios. No entanto, dar aula para qualquer turma o resultado, às vezes, não é conforme o programado, pois imprevistos sempre podem acontecer. Por mais que se fora tranquilo preparar a aula, de uma maneira que facilitasse o aprendizado dos alunos, alguns acadêmicos chegaram um pouco atrasados, quebrando a cadência da aula, circunstância esta que foi controlada no momento da explicação não extrapolando o horário previsto de aula.

Iniciar a docência significa um grande desafio e nos demanda uma nova postura perante a sociedade atual. A prática docente requer enorme esforço para se materializar de maneira a progredir de forma positiva, tanto no âmbito pessoal quanto no profissionalmente. Assim compreendeu-se que a formação do docente universitário requer a sua participação em programas de 
formação continuada com o intuito de qualificar ainda mais o processo ensinoaprendizagem.

Dessa forma, através de uma análise crítica da metodologia da estratégia e dos preceitos teóricos, foi possível elencar alguns aspectos e procedimentos práticos que auxiliariam, quando utilizados de maneira correta, na aplicação da estratégia apresentada. Não basta apenas saber bem utilizar uma estratégia de ensino, é necessário compreendê-la dentro de um contexto teórico e empírico. É nesse sentido que se dá destaque, no contexto dos problemas da atualidade quanto à formação do docente no ensino superior, à contribuição das estratégias de ensino que qualifiquem o futuro professor para a vida acadêmica.

\section{REFERÊNCIAS}

ALVEZ, F. L. P.; ROCHA, R. A.; OLIVEIRA, L. C. P. Endomarketing como ferramenta de estratégia empresarial. In: XXII ENCONTRO NACIONAL DE ENGENHARIA DE PRODUÇÃO. (ENEGEP), 23., 2002, Curitiba - PR.

ANASTASIOU, L. G. C.; ALVEZ, L. P. A. Processos de ensinagem na Universidade: Pressupostos para as estratégias de trabalho em aula. Joinvile: UNIVILE, 2005.

ANASTASIOU, L.G.C. Metodologia de ensino na universidade brasileira: elementos de uma trajetória. In: Castanho S, Castanho ME (orgs). Temas e textos em metodologia do ensino superior. Campinas: Papirus, 2001.

BASTOS, C. C. B. C.; ORO, M. C. P.. Formação pedagógica para docência universitária: estudo das condições de cursos bacharelados de uma ies pública. In: Anais IX SEMINÁRIO DE PESQUISA DA REGIÃO SUL (ANPED). 22, 2012, Caxias do Sul - RS

BIAJONE, J.;ALMEIDA, P. C. A. Saberes docentes e formação inicial de professores: implicações e desafios para as propostas de formação. Educação e Pesquisa. v.33, n.2, p. 281-295, 2007.

CUNHA, M. I. Docência Universitária. Trabalho Docente na Educação Básica no Brasil. Belo Horizonte: Autêntica, 2015.

GIL, Antonio Carlos. Metodologia do ensino superior. São Paulo: Ed. Atlas, 1994.

MARCONI, Marina de Andrade; LAKATOS, Eva Maria. Técnicas de pesquisa. In: Fundamentos de metodologia científica. São Paulo: Atlas, 2010. 
MIZUKAMI, M. G. N.;FERENC, A. V. F. Formação de professores, docência universitária e o aprender a ensinar. In: VIII CONGRESSO ESTADUAL PAULISTA SOBRE FORMAÇÃO DE EDUCADORES. 20, 2005, São Paulo.

MIZUKAMI, M. G. C. Ensino: abordagens e processos. São Paulo: EPU, 1986.

SANTOS, J; MEIRA, K.C. Operações de pensamento e estratégias de ensino: relações e complexidade como uma alternativa para tomada de decisão na dinâmica dos processos de ensino-aprendizagem. Revista Eletrônica Gestão \& Saúde. Vol. 6, n. 3, p.2024-38, 2015.

TARDIF, Maurice. Saberes docentes e formação profissional. Petrópolis, RJ: Vozes, 2007. 